\title{
Evaluation of chilling injury and internal browning condition on quality attributes, phenolic content, and antioxidant capacity during sub-optimal cold storage of Malaysian cultivar pineapples
}

\author{
Noer Hartini Dolhaji ${ }^{a,}{ }^{*}$, Ida Idayu Muhamad ${ }^{b}$, Harisun Ya'akub b, c, Azila Abd Aziz b, c \\ ${ }^{a}$ Faculty of Plantation and Agrotechnology, Universiti Teknologi MARA (UiTM) Jasin, Melaka, Malaysia \\ ${ }^{b}$ Faculty of Chemical and Energy Engineering, Universiti Teknologi Malaysia (UTM) Skudai, Johor, Malaysia \\ c Institute of Bioproduct Development, Universiti Teknologi Malaysia (UTM) Skudai, Johor, Malaysia \\ * Corresponding author: noerhartinidolhaji@gmail.com
}

Article history

Received 27 February 2018

Revised 28 Mac 2018

Accepted 21 May 2018

Published Online 16 December 2018

\begin{abstract}
Pineapple cold storage at sub-optimal temperature $\left(4 \pm 2{ }^{\circ} \mathrm{C}\right)$ and duration of storage $(0,7,14,21$, and 28 days) was periodically tracked to investigate its effect on physical injuries known as chilling injury $(\mathrm{Cl})$ and internal browning (IB), which contribute to degradation of pineapple's quality attributes (i.e., $\mathrm{pH}$, total soluble solids (TSS) concentration, ascorbic acid (AA) content, ion leakage (EL), antioxidant capacity, and total phenolic content (TPC). In this study, three main Malaysian pineapple cultivars were evaluated based on the hypothesis that pineapple's physical injuries $(\mathrm{Cl}$ and $\mathrm{IB}$ ) affect the quality attributes, phenolic content, and antioxidant capacity. Towards day 28 of sub-optimal cold storage treatment, cv. Morris (Queen) showed higher Cl and IB incidences. However, the incidences were not statistically significant at a significance level of 0.05 in two other pineapple varieties Cv. Josephine (hybrid, between 'Johor' Spanish and Smooth Cayenne) and cv. MD-2 or gold (the hybrid of Smooth Cayenne)), which exhibited resistance to $\mathrm{Cl}$ and IB. Meanwhile, it was found that sub-optimal cold storage up to 28 days affects $\mathrm{Cl}$ and IB of three main Malaysian pineapple cultivars regardless of their genetic capability towards these injuries. Further, the study revealed that $\mathrm{Cl}$ and IB symptoms were correlated with a decrease in TSS and $\mathrm{pH}$, and an increase in the percentage of EL, TPC, antioxidant capacity, and antioxidant activities measured by FRAP and DPPH, respectively. Meanwhile, in terms of overall quality attributes result with focus interaction of TPC and antioxidant capacity, CV. MD-2 was observed to be impacted the most during sub-optimal cold storage. The study concluded that $\mathrm{Cl}$ and IB conditions were positively correlated with the degradation of quality attributes as reflected in TSS content, pH, EL, TPC content, and total antioxidant capacity.
\end{abstract}

Keywords: Pineapple, chilling injury, sub-optimal temperature, quality attributes

\section{INTRODUCTION}

Pineapple (Ananas comosus) is a popular species from the family of Bromeliaceae that has been widely cultivated. This perennial species contributes to over $20 \%$ of the world production of tropical fruits. Malaysia classifies pineapple as one of its major commodity crops and lists pineapple production industry as its oldest agro-based industry in the country. Development of pineapple industry in Malaysia during the 1960s and 1970s has positioned Malaysia among the top three world producers of pineapples (Othman et al., 2011). Within two decades from the period of 1990 to 2012, the world has witnessed a 200\% global increase of pineapple production volume from 11.84 million metric tons (MT) to 23.33 million MT (Lobo \& Yahia, 2017). Beginning from the year 2015, Malaysian pineapple's farmers have shifted their production from supplying canned pineapple varieties to supplying fresh pineapple varieties attributed to higher returns (Zhao et al., 2012). Malaysia Pineapple Industrial Board projected a 5\% yearly increase in pineapple export volume from 20,278 tonnes in 2015 due to the high demand for fresh pineapples worldwide. Josapine, Morris, and MD-2 are among the most widely established fresh pineapple cultivars export by Malaysia.

In recent years, the effort has been made to assure high-quality pineapple products prior to entering the market as pineapples are acknowledged by its distinct flavour, juiciness, texture, vitamin $\mathrm{C}$ content, and fibre content (Abdullah, 2011). A high-quality pineapple is characterized from both its internal and external quality attributes. The external attributes are measured by size and weight and scaled by appearance whereas internal attributes are quantitated by its chemical characteristics, and qualitatively evaluated by its colour and textures (Suksawat, 2015). However, pineapples have high moisture content and their active metabolism leads to physical and nutritional deterioration after harvest (Hong et al., 2013). Research and development to preserve postharvest pineapple quality under cold storage have been widely reported including, postharvest methyl jasmonate treatment 
(Nilprapruck \& Pradisthakarn, 2008), heat treatment (Weerahewa \& Adikaram, 2005), temperature preconditioning (Abdullah et al., 2006), 1-Methylcyclopropene treatment (Setha et al., 2013), and edible coating (Selvarajah \& Herath, 1997). These studies have been developed to exploit the advantage of combining cold storage treatment and proposed pineapple preservation treatments as an alternative treatment which could potentially yield a better result in maintaining pineapple fruit quality than applying those treatments independently.

The temperature of storage by refrigeration is a critical parameter in pineapple postharvest for maintaining the freshness of the fruit for export as pineapple is a non-climacteric fruit which must be harvested ripe since the ripening process discontinues after harvest. Common postharvest physiological disorder of pineapple due to low temperature is chilling injury (CI). Under CI, observable symptoms include internal browning (IB) and black heart (BH) conditions (Hassan et al., 2011). Chilling injury may take place in two scenarios where fresh fruits are exposed to suboptimum storage temperature, and when storage duration is prolonged more than the restricted limit. Although metabolic dysfunction variations in pineapples are widely reported, there remain loopholes in the knowledge of CI that adequately characterize the occurrence of $\mathrm{CI}$ in pineapples (Luengwilai et al., 2016). Thus, this paper aims to investigate the effect of sub-optimal low-temperature storage on $\mathrm{CI}$ and IB, and duration of storage on quality attributes, antioxidant capacity, and phenolic content of Malaysian cultivars pineapple.

\section{MATERIALS AND METHODS}

\section{Preparation of plant materials}

Three pineapple cultivars characterized by distinct CI susceptibility levels (Morris-low susceptible, Josapine-partially susceptible and $M D$ 2-high susceptible) were chosen in this study. The fruits were purchased from local producers in Pontian, Johor, Malaysia. Pineapples are typically harvested at the mature-green stage of maturity (index 3), where the skin is still green with 1-2 eyes of the fruit have turned to yellow colour, based on Federal Agricultural Marketing Authority of Malaysia (FAMA). Fruits displaying acceptable features including the absence of disease signs and physical damage and weighed approximately $1.5-1.8 \mathrm{~kg}$ were washed, disinfected with sodium hypochlorite, and sprayed with a fungicide $\left(\mathrm{BENEX}^{\circledR}\right)$.

\section{Low-temperature treatment}

A completely randomized design was used in conducting the experiment through which 60 pineapples, each from cv. Morris, cv. Josapine, and cv. $M D-2$ were packed and randomly divided into three batches to be placed into a commercial cardboard box $(14$ × 32 × 49 $\mathrm{cm}$ ) for export (Zaulia \& Suhaila, 2007). The batches were stored at sub-optimal storage temperatures $\left(4 \pm 2^{\circ} \mathrm{C}\right)$ with $85 \pm 5 \%$ relative humidity (RH). Five pineapples were taken out of storage, each time on day $0,7,14,21$, and 28 for sampling. The sampling was repeated three times.

\section{Chilling Injury (CI) and internal browning (IB) score}

Chilling injury and browning symptoms were evaluated by observing the proportion (\%) of cut fruit section that displayed translucency due to water penetration and browning symptoms, respectively. Sub-optimally stored fruit was taken out of storage and restored to room temperature over a period of 24 hours, where it was then cut from the middle into halves, lengthwise (Abdullah, 2011). The symptoms were assessed through subjective scoring based on proportion $(\%)$ of cut fruit flesh that displayed water-penetrated translucency and browning area, measured by using callipers (Youryon, et al., 2013)

\section{Soluble solids concentration (TSS), $\mathrm{pH}$ and ascorbic acid}

Pineapple flesh (100 g) was sliced into small sections, homogenized, and filtered. The filtrate was used for measuring total soluble solids concentrations (TSS) and $\mathrm{pH}$. A hand-held digital refractometer was used to determine TSS in samples (Bellingham Stanley) and expressed in ${ }^{\circ}$ Brix scale (AOAC, 2000). A benchtop pH meter (Mettler Toledo) was used to measure fruit juice $\mathrm{pH}$ level.
Meanwhile, the AOAC (1995) method was used to measure the content of ascorbic acid (AA) in fruit. In determining AA content of fruit, a predetermined 2,6-dichloroindophenol solution volume used during titration was utilized in the calculation (Nukuntornprakit et al., 2015).

\section{Ion leakage}

Fruit flesh Ion leakage (EL) was analysed as per method described by Nukuntornprakit et al. (2015). $3.0 \mathrm{~g}$ of fresh pulp sample was cut into dices (Dimension: $0.5 \mathrm{~cm} \times 0.5 \mathrm{~cm} \times 0.5 \mathrm{~cm}$ ). The dices were washed and decanted three times with distilled water and added with $50 \mathrm{~mL}$ of $0.4 \mathrm{M}$ mannitol solution. Then, the sample was shaken for 1 hour at 100 r.p.m on an orbital shaker. Subsequently, a conductivity meter was used to measure conductivity (E1). Samples were allowed to lower their temperature to $25^{\circ} \mathrm{C}$ after autoclaving at $121 \mathrm{C}$ for 30 minutes. Re-measurement of conductivity (E2) was performed. The percentage is used to express actual EL by dividing the difference between pre-autoclaving (E1) and post-autoclaving (E2) with conductivity reading after samples were autoclaved (E2).

\section{Assay of total phenolic content (TPC)}

Folin-Ciocalteu assay was utilized to determine fruit extract total phenolic content (Yeoh \& Ali, 2017). Briefly, 2N Folin-Ciocalteu reagent $(0.5 \mathrm{ml})$, distilled water $(6.0 \mathrm{ml})$, and fruit extract $(0.1 \mathrm{ml})$ were mixed together. The mixture was placed in incubation for four minutes at room temperature, and further added with $1.9 \mathrm{ml}$ of distilled water and sodium carbonate $(7 \% \mathrm{w} / \mathrm{v})$. At $37^{\circ} \mathrm{C}$, the mixture solution was stirred using a vortex shaker and allowed to incubate for two hours. Distilled water $(0.1 \mathrm{ml})$ was used to replace fruit extract $(0.1 \mathrm{ml})$ in preparation of blank. Microplate spectrophotometer with wavelength set at $765 \mathrm{~nm}$ was used to measure blue colored-complex formation on samples, quantified as absorbance value, which was then compared against blank. Similar procedures were utilized in standard curve preparation whereby gallic acid as a standard was used (concentration 100-1000 $\left.\mathrm{gml}^{-1}\right)$. The standard curve was used to compare TPC of fruit expressed in mg of gallic acid equivalents (GAE) $100 \mathrm{~g}^{-1} \mathrm{FW}$.

\section{Assay of ferric reducing antioxidant power (FRAP)}

FRAP method described by Benzie and Strain (1996) was used with some modification. Scavenging capacity was assessed by mixing $20 \mu \mathrm{L}$ extract with $200 \mu \mathrm{L}$ of FRAP working solution $[25 \mathrm{~mL}$ of $0.3 \mathrm{M}$ acetate buffer (pH 3.6) and $2.5 \mathrm{~mL}$ of $10 \mathrm{mM} \mathrm{2,4,6-tripyridyl-s-triazine} \mathrm{(TPTZ)}$ in $40 \mathrm{mM}$ hydrochloric acid, and $2.5 \mathrm{~mL}$ of $20 \mathrm{mM}$ ferric chloride solution $\left.\left(\mathrm{FeCl} 3.6 \mathrm{H}_{2} \mathrm{O}\right)\right]$ into a 96-well microplate. The mixture was incubated at $37^{\circ} \mathrm{C}$ for $4 \mathrm{~min}$. Blank was prepared by replacing $20 \mu \mathrm{L}$ of polyphenol extract with $20 \mu \mathrm{L}$ of distilled water. The absorbance value of a blue-colored complex formed was measured against a blank at $593 \mathrm{~nm}$ using microplate spectrophotometer. The experiment was performed similarly in the preparation of standard curve by using different concentrations of iron (II) sulphate $(100-1000 \mu \mathrm{M})$. The results were expressed in $\mathrm{mmol} \mathrm{Fe}^{2+} \mathrm{g}^{-1} \mathrm{FW}$.

\section{Total antioxidant activity 2,2-Diphenyl-1-picrylhydrazyl (DPPH)}

Antioxidant activity was determined by using 2,2-diphenyl-1picryl-hidrazyl (DPPH) radical-scavenging method (Yeoh \& Ali, 2017). $0.025 \mathrm{~g} \mathrm{~L}^{-1}$ of methanolic DPPH was freshly prepared before analysis. A $20 \mu \mathrm{L}$ of aliquot of the extract was mixed with $200 \mu \mathrm{L}$ of DPPH in a 96-well microplate and incubated in the dark at room temperature for 30 minutes. Blank was prepared by replacing $20 \mu \mathrm{L}$ of extract with $20 \mu \mathrm{L}$ of methanol. The absorbance value was measured at $517 \mathrm{~nm}$ using microplate spectrophotometer. Following equation which calculates DPPH inhibition percentage was used to determine total antioxidant activity in fruit:

\section{DPPH scavenging effect $(\%$ inhibition $\left.)=[(\mathrm{A} 0-\mathrm{A} 1) / \mathrm{A} 0)^{*} 100\right]$}

Where, A1 represents extract samples absorbance, while A0 represent blank absorbance. The experiment was replicated three times. Subsequently, data findings from the three replications were averaged. 


\section{Statistical analysis}

Statistical analysis was used to analyze all data. This tool also describes the relationship between the independent and dependent variables. For this research work, one-way ANOVA and independent paired t-test data analysis were performed using SPSS software (20th version). Statistical significance at $95 \%$ confidence level was used in drawing conclusions on main and interaction effects among the variables investigated.

\section{RESULTS}

\section{Chilling Injury (CI) and Internal Browning (IB)}

Chilling injury (CI) symptoms were observed after seven days of storage both in cv. Josapine and Morris, and later in cv. MD-2 after 14 days. CI was visible upon inspection beginning from pulp side of flesh surrounding the central axis, where translucency of flesh tissue became more apparent as the area penetrated by water formed water patches which indicated cell death (Fig. 1). The condition progressed, subsequently turning the flesh slightly brown (internal browning) starting from day 21. From day 21 of storage onwards, CI and IB symptoms spread further and increased tremendously.
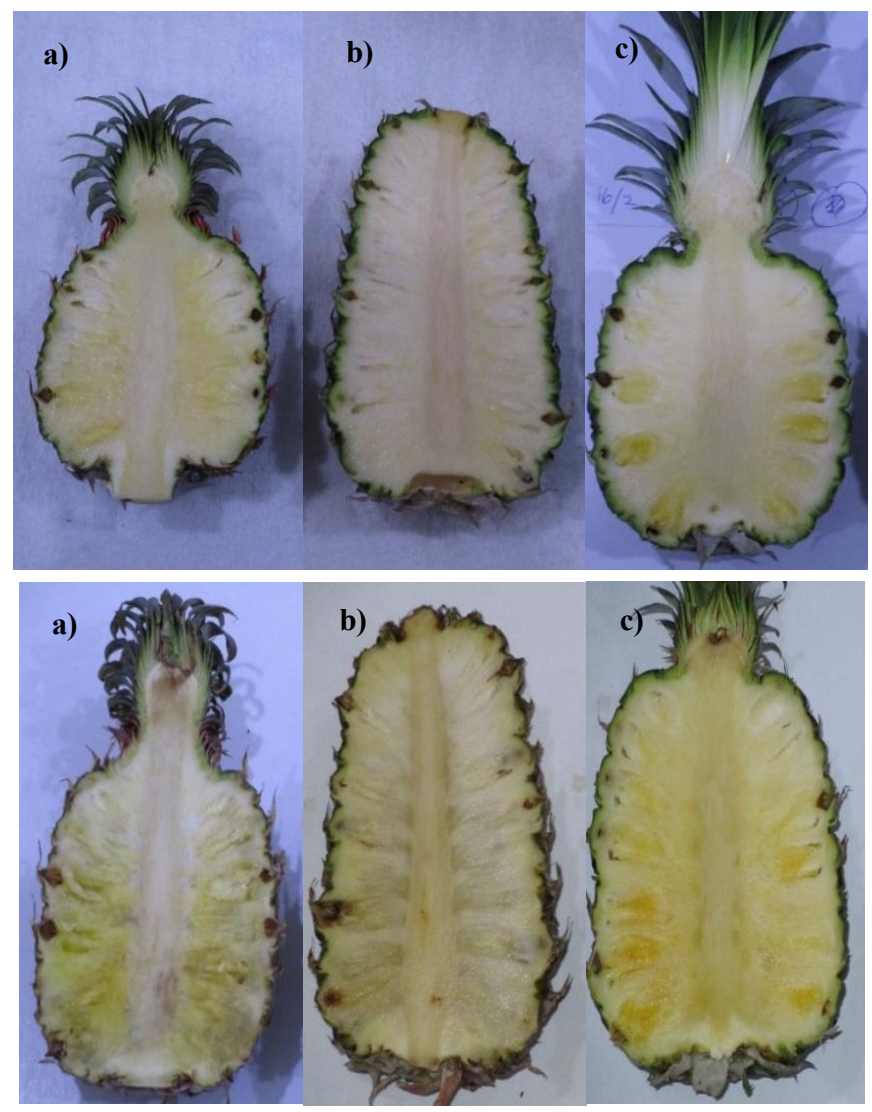

Fig. 1 Development of $\mathrm{Cl}$ and IB in a) Josapine, b) Morris, and c) $M D-2$ cv. pineapple during storage at $4 \pm 2{ }^{\circ} \mathrm{C}$ at 0 days (above) and 28 days (below).

There was a significant difference $(\mathrm{p}<0.05)$ in terms of CI and IB development, observed between cv. Josapine as compared to others on day 21 (Table 1). To understand the impact of CI and IB for all samples, monitoring was extended up to 28 days. The CI and IB impact on cv. Josapine was found to increase 8.0 folds from $3.33 \pm 2.88$ to $26.33 \pm$
0.75 at day 28 as compared to cv. Morris and cv. MD-2 which had an increase of 3.0 folds and 2.8 folds, respectively.

Table 1 Chilling injury $(\mathrm{Cl})$ and internal browning (IB) score symptoms $(\%)$ in 3 cultivars pineapple (Ananas comosus cv. 'Josapine', 'Morris' and 'MD2') stored at $4 \pm 2{ }^{\circ} \mathrm{C}$ from 0 to 28 days.

\begin{tabular}{cccccc}
\hline Cultivars & \multicolumn{5}{c}{ Cl, IB Score (\%) } \\
& $0 \mathrm{~d}$ & $7 \mathrm{~d}$ & $14 \mathrm{~d}$ & $21 \mathrm{~d}$ & $28 \mathrm{~d}$ \\
Josapine & $0.00 \pm$ & $0.67 \pm$ & $1.33 \pm$ & $3.33 \pm$ & $26.33 \pm$ \\
& $0.00^{\mathrm{a}}$ & $1.07^{\mathrm{a}}$ & $1.08^{\mathrm{a}}$ & $2.88^{\mathrm{a}}$ & $0.75^{\mathrm{a}}$ \\
& & & & & \\
Morris & $0.00 \pm$ & $1.33 \pm$ & $2.66 \pm$ & $9.66 \pm$ & $27.67 \pm$ \\
& $0.00^{\mathrm{a}}$ & $1.96^{\mathrm{a}}$ & $1.98^{\mathrm{a}}$ & $2.62^{\mathrm{b}}$ & $2.57^{\mathrm{a}}$ \\
& & & & & \\
MD-2 & $0.00 \pm$ & $0.00 \pm$ & $2.00 \pm$ & $8.33 \pm$ & $23.00 \pm$ \\
& $0.00^{\mathrm{a}}$ & $0.00^{\mathrm{a}}$ & $1.88^{\mathrm{a}}$ & $1.24^{\mathrm{b}}$ & $1.05^{\mathrm{a}}$ \\
\hline
\end{tabular}

Morris cv. showed consistently higher CI and IB symptoms. However, at day 28 the severity of CI and IB were not significantly different from others. For $M D-2 \mathrm{cv}$., the $\mathrm{CI}$ and IB symptoms showed the lowest percentage beginning from day 0 of sub-optimal storage due to its low susceptibility to CI and IB. Towards day 28, CI and IB symptom were similar for all cultivars.

\section{TSS Content}

The TSS content increased gradually for seven days and declined slowly afterwards across all three cultivars. TSS is often used as an indicator of fruit quality and maturity level. According to D'Eeckenbrugge \& Leal (2003), a minimum of $12 \%$ Brix is required for customer acceptance of pineapple fruits. Morris cv. stored at suboptimal temperature showed the lowest content of TSS with a statistically significant difference $(\mathrm{p}<0.05)$ at day 0,7 , and 14 , as compared to another cv. However, at day 28, TSS value for Morris cv increased from 8.83 to $9.13 \%$ Brix. Meanwhile, Josapine and $M D-2$ showed a slight decrease in TSS content, 0.6 and $0.1 \%$ Brix, respectively (Fig. 2).

\section{$\mathrm{pH}$}

$\mathrm{pH} 3$ in pineapple cv. showed a declining trend with respect to the day of storage at sub-optimal temperature. At day $0, M D-2$ was found to have the lowest $\mathrm{pH}$ value with $\mathrm{pH} 3.79$, which was significantly different $(\mathrm{p}<0.05)$ from others. On subsequent days, the $\mathrm{pH}$ values for Josapine, Morris, and MD-2 dropped to $13.5 \%, 26.9 \%$, and $13.45 \%$, respectively, from the initial $\mathrm{pH}$ value.

\section{Ascorbic Acid content}

The content of ascorbic acid was significantly higher $(\mathrm{p}<0.05)$ in $M D-2 \mathrm{cv}$. at 0 days of storage with $0.44 \mathrm{mg} / \mathrm{mL}$ of fresh pineapple juice as compared to other cvs. However, the amount of AA gradually decreased on subsequent days till day 28. On the other hand, both Josapine and Morris cv. showed a similar increasing trend of AA content where the amount significantly increased until day 7 and later decreased gradually.

\section{Ion leakage}

Ion leakage (IE) in pulp tissue across three cv. showed a lower percentage prior to storage, where IE for $M D-2 \mathrm{cv}$. Josapine $\mathrm{cv}$., and Morris cv. are $43.52 \pm 0.21 \%, 43.78 \pm 0.95 \%$, and $45.41 \pm 0.16 \%$, respectively. In overall, there was a significant increase in IE values (Fig. 2) of all cultivars whereby Josapine $c v$. showed the highest increase in IE percentage (65.9\%), followed by Morris (63.4\%), and $M D-2(45 \%)$. 

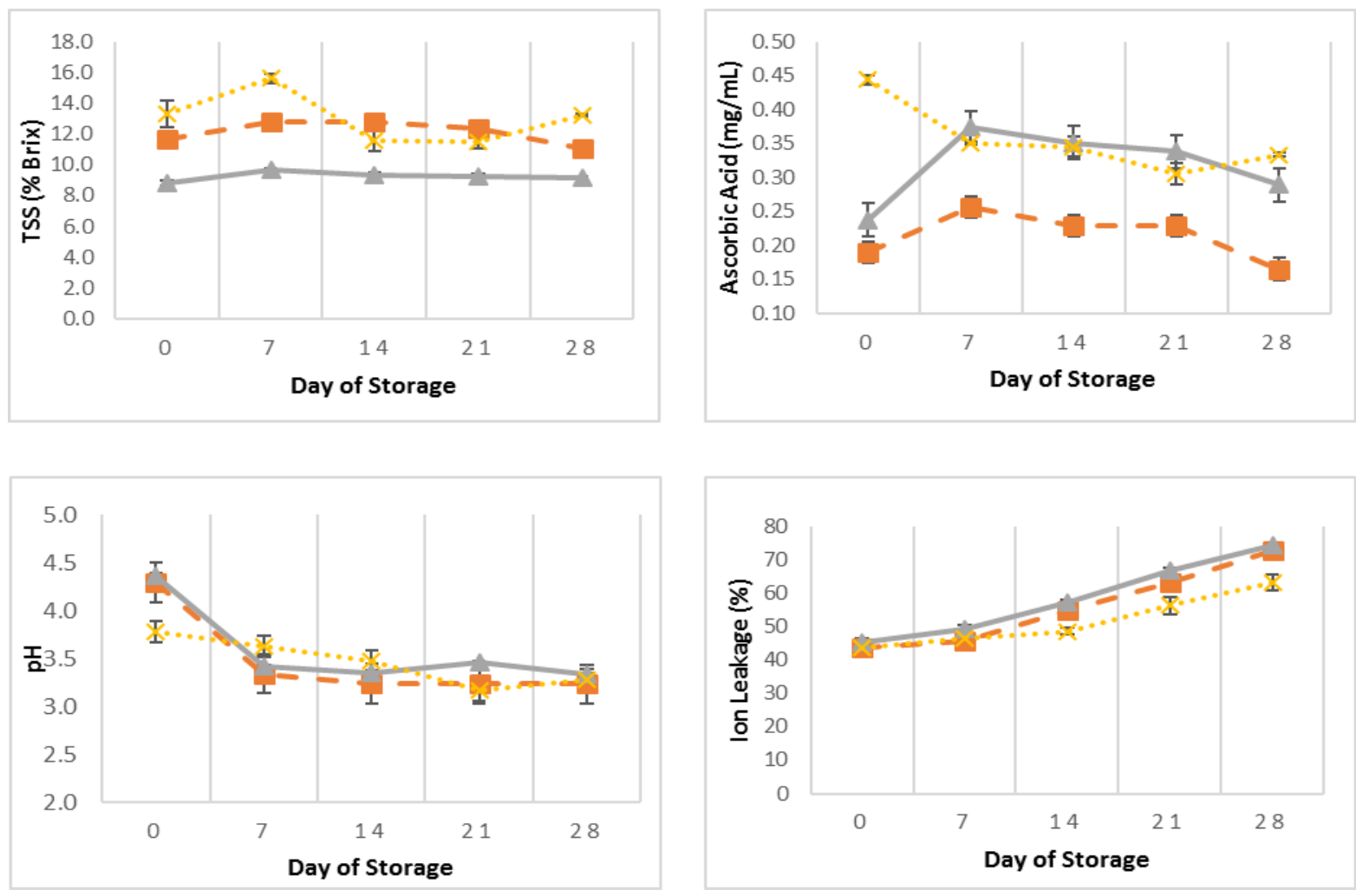

Fig. 2 Total soluble solids (TSS) concentration in \% Brix (A), ascorbic acid concentration ( $\mathrm{mg} / \mathrm{mL})(B), \mathrm{pH}(\mathrm{C})$, and ion leakage (\%), in cv. Josapine $(-----)$, Morris $(--\triangle--)$ and $M D-2\left(\cdots \times x^{\circ}\right)$ pineapples, stored at $4 \pm 2{ }^{\circ} \mathrm{C}$ for day $0,7,14,21$, and 28.

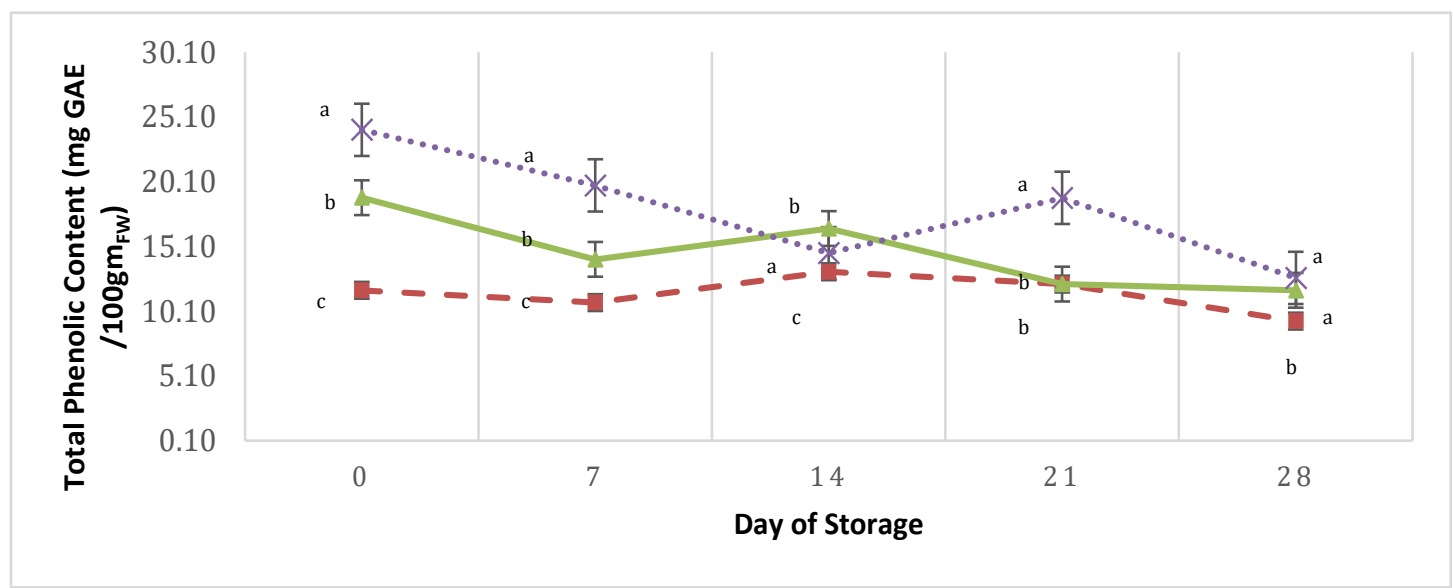

Fig. 3 Total phenolic content (mg GAE/100gm Fw) concentration in cv. Josapine (------), Morris (--- $\Delta---)$ and MD-2 ( $\bullet \bullet x \cdots \bullet)$ pineapples, stored at $4 \pm$ $2{ }^{\circ} \mathrm{C}$ for $0,7,14,21$ and 28 days. Value (mean \pm SE) of three repetitions (every repetition consisted of five pineapples) and statistical significance $(p<0.05)$ for every storage duration is marked by different alphabets.
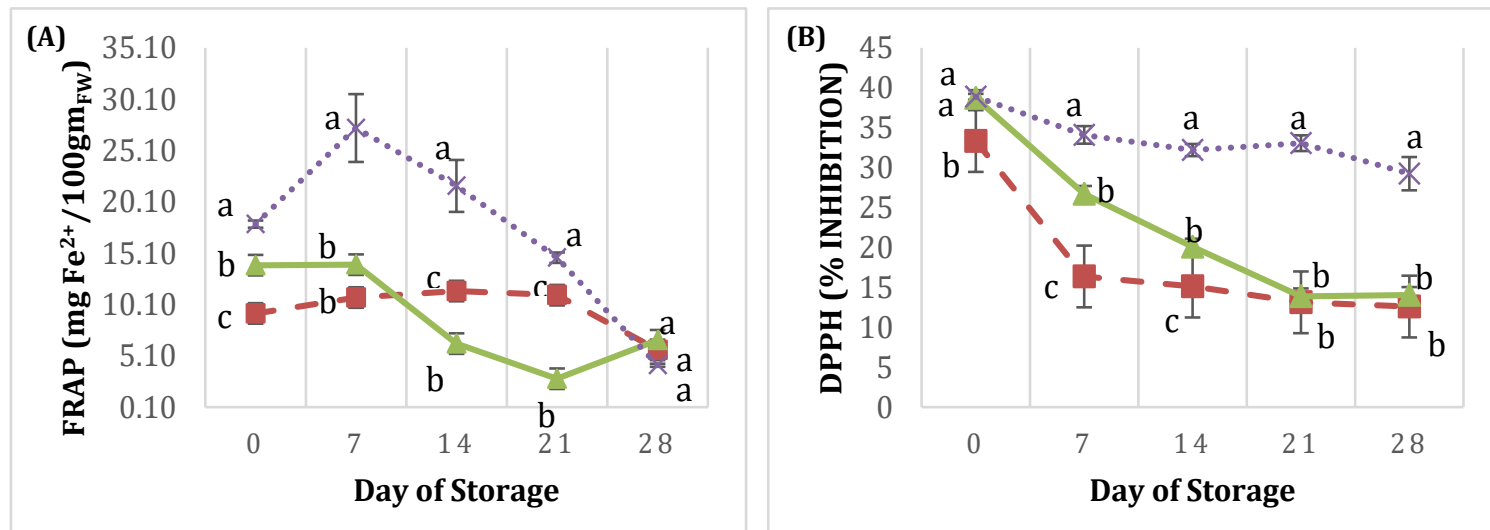

Fig. 4 FRAP $\left(\mathrm{mgFe}^{2+} / 100 \mathrm{gm}_{\mathrm{Fw}}\right)$ (A) and DPPH (\% inhibition) (B) in cV. Josapine (-------), Morris (--- $\left.\triangle---\right)$ and MD $2\left(\cdots \times x^{\circ} \cdots\right)$ pineapples, stored at 4 $\pm 2{ }^{\circ} \mathrm{C}$ for $0,7,14,21$ and 28 days. Value (mean $\pm \mathrm{SE}$ ) of three repetitions (every repetition consisted of five pineapples) and statistical significance $(p<0.05)$ for every storage duration is marked by different alphabets. 


\section{Total phenolic content}

The correlation of sub-optimal temperature and day of storage on total phenolic content (TPC) is illustrated in Fig..3. Prior to storage, phenol content was in the range of 11.71 and $24.10 \mathrm{mg} \mathrm{GAE} / 100 \mathrm{gm} F \mathrm{~F}$. By day 28, phenol content decreased in the range of 9.33 and $12.67 \mathrm{mg}$ GAE/100 gmFw. At day 28, TPC in MD-2 and Morris $c v$ had significantly decreased $(\mathrm{p}<0.05)$ from $24.01 \pm 2.11$ and $18.86 \pm 2.18$ to $12.66 \pm 1.72$ and $11.71 \pm 0.82 \mathrm{mg} \mathrm{GAE} / 100 \mathrm{gm}_{\mathrm{FW}}$, respectively.

\section{Antioxidant capacity}

FRAP assay detects ferric tripyridyltriazine complex $\left(\mathrm{Fe}^{3+}-\mathrm{TPTZ}\right)$ reduction to ferrous tripyridyltriazine complex $\left(\mathrm{Fe}^{2+}-\mathrm{TPTZ}\right)$ that produces a blue color. This assay is useful to measure an antioxidant's reducing potential. In this study, it was found that pineapple extract showed a slight increase in antioxidant capacity measured by FRAP assay at 7 days of storage in both Morris and Josapine cv. from 13.93 and $9.23 \mathrm{mg} \mathrm{Fe}{ }^{2+} / 100 \mathrm{gm}_{\mathrm{FW}}$ to 13.98 and $10.78 \mathrm{mg} \mathrm{Fe}^{2+} / 100 \mathrm{gm}_{\mathrm{FW}}$, respectively (Fig. 4). However, for $M D-2 \mathrm{cv}$. FRAP value increased by 1.2 folds from 17.93 to $27.29 \mathrm{mg} \mathrm{Fe}{ }^{2+} / 100 \mathrm{gm}$ Fw. In overall, antioxidant capacity measured by using FRAP assay across all cultivars decreased gradually from day 7 onwards.

DPPH assay was carried out to assess antioxidant's scavenging ability towards DPPH. The extent of discoloration of sample antioxidant indicates scavenging ability (Ali, Almagribi, \& Al-Rashidi, 2016). Antioxidant discoloration occurs due to the reaction of a stable free radical, $\alpha, \alpha$-diphenyl- $\beta$ - picrylhydrazyl (dark hue of violet) with an antioxidant, resulting in a discolored $\alpha$-diphenyl- $\beta$ - picrylhydrazine. In the present study, $M D-2 \mathrm{cv}$. showed the lowest reduction of scavenging activity throughout 28 days of storage with $24.6 \%$ reduction as compared to Josapine and Morris cv. with $62.16 \%$ and $63.79 \%$ reduction, respectively (Fig. 4).

\section{DISCUSSION}

Temperature is the single most critical factor in horticultural fruits storage including pineapple. Almost all biological processes in fruits are controlled by temperature, thus fruit quality and shelf-life are strongly affected by this factor (Hong et al., 2013). Although the temperature is beneficial to fruits, it is restricted by physical defects associated with CI where recommended optimal temperature for pineapple storage is in the range of 8 to $10{ }^{\circ} \mathrm{C}$ (Hassan et al., 2011). The present study has shown that 3 common Malaysian pineapple cultivars for export were subjected to CI and IB symptoms after being stored at the sub-optimal temperature $\left(4 \pm 2{ }^{\circ} \mathrm{C}\right)$. Despite this, it is known that $M D-2$ and Josapine cv. are resistant to IC and IB. The previous study by Luengwilai, et al. (Luengwilai et al., 2016) reported MD-2 showed no symptoms of IC and IB when stored at $10{ }^{\circ} \mathrm{C}$, up to 3 weeks of storage. However, in the present study, storage at suboptimal temperature challenged the cultivars' biological resistant ability towards IC and IB symptoms beginning from day 14 Statistically, the significant increase was observed $(\mathrm{p}<0.05)$ on day 21 . Morris, and Queen type cv. which are highly susceptible to CI and IB showed visible symptoms beginning from day 7 of storage at a suboptimal temperature in agreement with Stewart et al. (Stewart et al., 2002) while Josapine cv. showed moderate CI and IB symptoms until day 21.

Meanwhile, TSS concentration increased slightly and remained higher at day 7 of storage for all cultivars. Similar results reported by Hong et al., 2013) indicated that pineapple stored at $6{ }^{\circ} \mathrm{C}$ showed an increasing trend in TSS value and subsequently declined gradually. The current study showed a similar trend for all cultivars where TSS concentration started to slightly decrease from day 7 day but remained insignificantly different $(p<0.05)$ from 0 days of storage. This result could be attributed to low respiratory activity occurring at very low temperature thus sugar remained unused for the respiratory process. TSS is an important quality factor for many fruits including pineapple as an indication of fruit maturity and physical quality (Hajar et al., 2012). As sugar is one of the most important constituents for determining the quality of pineapple, study by Chen \& Paull (2000) revealed that sugar accumulation and activities of sugar-metabolizing enzymes are related to the occurrence of pineapple flesh translucency.
$\mathrm{pH}$ value of all three cultivars in the present study showed a slow decline along progressing day of storage. Morris cv. showed a significant difference $(\mathrm{p}<0.05)$, where it had the highest $\mathrm{pH}$ as compared to other cultivars, beginning from day 21 days to day 28 . According to Shamsudin et al. (2007) acceptable pineapple $\mathrm{pH}$ ranges from 3.3 to 3.7. Ascorbic acid (AA) content was found to be at peak for Morris and Josapine cv. during the first seven days and gradually decreased towards the end of day 28. MD-2 showed the highest content of AA prior to storage at $0.44 \mathrm{mg} / 100 \mathrm{gm}_{\mathrm{Fw}}$, in which Smooth Cayenne is well known for its high source of AA compared to others (Ramsaroop \& Saulo, 2007). All cultivars showed a similar trend of slowly declining AA content. Josapine cv. was significantly the lowest as compared to others beginning from day 14 . Study by Lee \& Kader (2000) found a lower ascorbic acid content in pineapple is associated with higher susceptibility to CI under storage temperatures below $7^{\circ} \mathrm{C}$. The IE is the key indicator of membrane damage and loss of membrane integrity due to respiration rate (Shadmani et al., 2015). The gradual increase of IE on all pineapples cultivars showed that the trend of membrane damage increased with longer days of storage.

In fruits and vegetables, the phenolic compound is widely distributed and contributes to antioxidant intake and is presumed to have a health protective action in humans (Hossain \& Rahman, 2011). In the present study, sub-optimal temperature storage was found to affect TPC with a decreasing trend in all pineapple cultivars. Josapine cv. showed a significantly lower TPC than others at day 28. Overall regression analysis showed that a decrease in TPC was positively correlated $(r=0.176, p<0.05)$ with IC and IB incidence percentage throughout sub-optimal cold storage. The chilling process during storage activity induced oxidative injury. Oxidative-related disorder will occur when fruits are subjected beyond their temperature thresholds. A review by Kusvuran et al. (2016) reported chilling damage in fruits was associated with oxidative stress from excess reactive oxygen species (ROS) which further caused a membrane damage. Furthermore, a review by Blokhina et al. (2013) revealed plant tissues with better antioxidant systems would be more resistant against low temperatures (Blokhina et al., 2003). The current study utilized FRAP which measures antioxidant power by electron transfer reaction that results in a reduction of oxidant color.

In Fig. 4, a decreasing trend of FRAP value for all cultivars was evident with $M D-2$ being significantly affected by storage time. A positive correlation was found between FRAP, TSS, and AA values which is consistent with the findings of (Kalt et al., 1999; Kulkarni \& Aradhya, 2005) which reported that antioxidant capacity through postharvest would affect ascorbate and TSS content.

Another antioxidant capacity by DPPH showed a similar trend of decreasing percentage of DPPH inhibition throughout 28 days of study, with $M D-2$ exhibiting a lower decreasing trend as compared to others. The result indicates that a lower DPPH inhibition is related to lower CI and IB scores. This result is consistent with previous work by (Nukuntornprakit et al., 2015) which reported that the development of CI and IB symptoms was correlated with ROS metabolism, which was reflected in total antioxidant capacity.

\section{CONCLUSION}

In conclusion, it was observed that sub-optimal cold storage up to 28 days affects $\mathrm{CI}$ and IB on three Malaysian most exported cultivars regardless of their genetic capability against the injuries. It was demonstrated that Morris cv. was the most affected by CI and IB symptoms throughout 28 days of study followed by Josapine cv. However, in overall, $M D$-2's quality attributes exhibited the most vulnerability with low resistivity to sub-optimal cold storage during postharvest and cold chain transportation which majorly influence its TSS content, AA content, phenolic content, and antioxidant capacity. These findings provide crucial insights in supporting existing information on three main Malaysian pineapple cultivars in the effort to revive Malaysian pineapple especially toward fulfilling global exporting market. 


\section{ACKNOWLEDGEMENT}

This research was fully funded by Project no. RJ130000.7846.4F726 of Food and Biomaterial Engineering Research Group (FOBERG), University Technology of Malaysia (UTM).

\section{REFERENCES}

Abdullah, H. 2011. Quality maintenance of pineapple in postharvest handling. Acta Horticulturae, 902, 403-408.

Abdullah, H., Rohaya, M. A., Engku Hasmah, E. A. 2006, 2008. Increasing pineapple fruit resistance to chilling injury during storage by temperature preconditioning. Acta Horticulturae, 768, 217-224

Ali, H. M., Almagribi, W., Al-Rashidi, M. N. 2016. Antiradical and reductant activities of anthocyanidins and anthocyanins, structure-activity relationship and synthesis. Food Chemistry, 194, 1275-1282.

Benzie, I. F., Strain, J. J. 1996. The ferric reducing ability of plasma (frap) as a measure of "antioxidant power": The frap assay. Analytical Biochemistry, 239(1), 70-76.

Blokhina, O., Virolainen, E., Fagerstedt, K. V. 2003. Antioxidants, oxidative damage and oxygen deprivation stress: A review. Annals of Botany (Special Issue Janиary), 91, 179-194.

Chen, C.-c., Paull, R. E. 2000. Sugar metabolism and pineapple flesh translucency. Journal of the American Society for Horticultural Science, 125(5), 558-562.

D'Eeckenbrugge, G., Leal, F. 2003. The pineapple botany, production and uses. CABI, Wallingford, Oxon, 13-32

Hajar, N., Zainal, S., Nadzirah, K. Z., Roha, S., Atikah, O., Elida, T. Z. M. 2012. Physicochemical properties analysis of three indexes pineapple (Ananas comosus) peel extract variety n36. APCBEE Procedia, 4(4), 115-121.

Hassan, A., Othman, Z., Siriphanich, J. 2011. Postharvest Biology and Technology of Tropical and Subtropical Fruits. Volume 4: Mangosteen to White Sapote. Woodhead Publ. Ltd., Cambridge, 194-217.

Hong, K., Xu, H., Wang, J., Zhang, L., Hu, H., Jia, Z., et al. 2013. Quality changes and internal browning developments of summer pineapple fruit during storage at different temperatures. Scientia Horticulturae, 151, 68-74

Hossain, M. A., Rahman, S. M. M. 2011. Total phenolics, flavonoids an antioxidant activity of tropical fruit pineapple. Food Research International, 44(3), 672-676.

Kalt, W., Forney, C. F., Martin, A., Prior, R. L. 1999. Antioxidant capacity, vitamin $\mathrm{C}$, phenolics, and anthocyanins after fresh storage of small fruits. Journal of Agricultural and Food Chemistry, 47(11), 4638-4644.

Kulkarni, A. P., Aradhya, S. M. 2005. Chemical changes and antioxidant activity in pomegranate arils during fruit development. Food Chemistry, 93(2), 319324.

Kusvuran, S., Kiran, S., Ellialtioglu, S. S. 2016. Antioxidant enzyme activities and abiotic stress tolerance relationship in vegetable crops IntechOpenScience. Abiotic and Biotic Stress in Plants - Recent Advance and Future Perspectives, 481-506.

Lee, S. K., Kader, A. A. 2000. Preharvest and postharvest factors influencing vitamin C content of horticultural crops. Postharvest Biology and Technology, 20(3), 207-220.
Lobo, M. G., Yahia, E. 2017. Biology and postharvest physiology of pineapple. Handbook of Pineapple Technology: Production, Postharvest Science, Processing and Nutrition 1st edition. John Wiley \& Sons, Ltd.

Luengwilai, K., Beckles, D. M., Siriphanich, J. 2016. Postharvest internal browning of pineapple fruit originates at the phloem. Journal of Plant Physiology, 202, 121-133.

Nilprapruck, P., Pradisthakarn, N. 2008. Effect of exogenous methyl jasmonate on chilling injury and quality of pineapple (Ananas comosus 1.) cv. Pattavia. Science, 2(2), 33-42.

Nukuntornprakit, O. a., Chanjirakul, K., van Doorn, W. G., Siriphanich, J. 2015. Chilling injury in pineapple fruit: Fatty acid composition and antioxidant metabolism. Postharvest Biology and Technology, 99, 20-26.

Othman, M. H., Buang, L., Mohd Khairuzamri, M. S. 2011. Rejuvenating the Malaysian pineapple industry. Acta Horticulturae, 902, 39-52.

Ramsaroop, R. E. S., Saulo, A. A. 2007. Cayenne pineapple cultivars. Journal of Food Quality, 30, 135-159.

Selvarajah, S., Herath, H. M. W. 1997. Effect of an edible coating on some quality and physicochemical parameters of pineapple during cold storage. Tropical Agricultural Research, 9, 77-89.

Setha, S., Kongsuwan, A., Srilaong, V., 2013. Reduced internal browning in pineapple fruit by $1-\mathrm{MCP}$ pretreatment and the antioxidant response. Acta Horticulturae. 1021, 573-580.

Shadmani, N., Ahmad, S. H. H., Saari, N., Ding, P., Tajidin, N. E. E. 2015. Chilling injury incidence and antioxidant enzyme activities of Carica papaya 1 . 'Frangi' as influenced by postharvest hot water treatment and storage temperature. Postharvest Biology and Technology, 99, 114-119.

Shamsudin, R., Daud, W. R. W., Takriff, M. S., Hassan, O. 2007. Physicochemical properties of the josapine variety of pineapple fruit. International Journal of Food Engineering, 3(5), 1-12.

Stewart, R. J., Sawyer, B. J. B., Robinson, S. P. 2002. Blackheart development following chilling in fruit of susceptible and resistant pineapple cultivars. Australian Journal of Experimental Agriculture, 42(2), 195-199.

Suksawat, B. 2015. Pineapple quality grading using image processing and fuzzy logic. International Conference on Control, Automation and Robotics, 218222.

Weerahewa, D., Adikaram, N. K. B. 2005. Heat-induced tolerance to internal browning of pineapple (Ananas comosus cv. 'Mauritius') under cold storage. Journal of Horticultural Science and Biotechnology, 80(4), 503-509.

Yeoh, W. K., Ali, A. 2017. Ultrasound treatment on phenolic metabolism and antioxidant capacity of fresh-cut pineapple during cold storage. Food Chemistry, 216, 247-253.

Youryon, P., Wongs-Aree, C., McGlasson, W. B., Glahan, S., Kanlayanarat, S. 2013. Alleviation of internal browning in pineapple fruit by peduncle infiltration with solutions of calcium chloride or strontium chloride under mild chilling storage. International Food Research Journal, 20(1), 239-246.

Zaulia, O., Suhaila, M. 2007. Effect of various coatings on the chemical changes of different pineapple cultivars (n36 and gandul) at low-temperature storage. Journal of Tropical Agriculture and Food Science, 35(1), 107-120.

Zhao, S. X., Chan, R. C., Chan, N. Y. M. 2012. Spatial polarization and dynamic pathways of foreign direct investment in China 1990-2009. Geoforum, $43(4), 836-850$. 